\title{
Improving the Theranostic Potential of Exendin 4 by Reducing the Renal Radioactivity Through Brush Border Membrane Enzyme-Mediated Degradation
}

Mingru Zhang ${ }^{1,2}$, Orit Jacobson ${ }^{2}$, Dale O. Kiesewetter ${ }^{2}$, Ying $\mathrm{Ma}^{2}$, Zhantong Wang ${ }^{2}$, Lixin Lang ${ }^{2}$, Longguang Tang ${ }^{2}$, Fei Kang ${ }^{1,2}$, Hongzhang Deng ${ }^{2}$, Weijing Yang ${ }^{2}$, Gang $\mathrm{Niu}^{2}$, Jing Wang ${ }^{1, *}$, Xiaoyuan $\mathrm{Chen}^{2,{ }^{*}}$

1. Department of Nuclear Medicine, Xijing Hospital, Fourth Military Medical University, Xi'an, Shannxi,710032, China

2. Laboratory of Molecular Imaging and Nanomedicine, National Institute of Biomedical Imaging and Bioengineering, National Institutes of Health, Bethesda, Maryland, 20892, USA

\section{Corresponding author}

Dr. Xiaoyuan Chen

LOMIN/NIBIB/NIH, 35A Convent Drive 35A/GD937, Bethesda, MD, 20892, 301-451-4246

shawn.chen@nih.gov

Dr. Jing Wang

127\# Changle West Road, department of Nuclear Medicine, Xijing Hospital, Xi'an, 710032, 02984775449

wangjing@fmmu.edu.cn 


\section{MATERIALS AND METHODS}

\section{Chemistry}

Synthesis of NOTA-Cys ${ }^{40}-$Leu$^{14}$-Exendin 4 and NOTA-MVK-Cys ${ }^{40}-\mathrm{Leu}^{14}$ Exendin 4

$\mathrm{Cys}^{40}{ }^{4}$ Leu $^{14}$-Exendin 4 (10 mg, 1 eq.) was dissolved in $1 \mathrm{~mL}$ de-gassed $0.1 \% \mathrm{Na}$ ascorbate (w/v) in phosphate buffer-saline (PBS). Either Maleimide-NOTA (1.2 mg, $1.2 \mathrm{eq})$ or NOTA-MVK-Maleimide (2.6 mg, $1.2 \mathrm{eq})$ was dissolved in $0.2 \mathrm{~mL}$ DMSO and added to the reaction solution. The reaction was stirred at room temperature for 2 $\mathrm{h}$ and purified by preparative HPLC. The target compounds were obtained in a chemical purity $>95 \%$ and a yield of $50-68 \%$. The retention time (r.t.) of NOTA-Cys ${ }^{40}-\mathrm{Leu}^{14}$ Exendin 4 and NOTA-MVK-Cys ${ }^{40}$-Leu ${ }^{14}$-Exendin 4 on analytical HPLC using method B was 15.2 and $15.5 \mathrm{~min}$, with mass of 4694 and $5176[\mathrm{M}+\mathrm{H}]^{+}$respectively.

\section{Synthesis of Boc-MVK-Dde}

The loading of the first amino acid of fmoc-Lys(Dde)-OH to 2-chlorotrityl chloride resin was performed following the published procedure ${ }^{1}$. Boc-MVK-Dde was synthesized on a peptide synthesizer with Fmoc-Lys(Dde)- 2-chlorotrityl chloride resin ( $0.5 \mathrm{~g}, 1$ eq.) as the starting material. Fmoc-Val-OH and Boc-Met-OH was constructed to the chain under the standard protocol of (i) $1 \mathrm{~h}$ of coupling of the protected amino acid derivative (4 eq.) in the presence of 2-(1h-benzotriazole-1-yl)-1,1,3,3tetramethyluronium hexafluorophosphate (HATU, 4 eq.) and N,NDiisopropylethylamine (DIPEA, 4 equiv.) in N,N'-dimethylformamide (DMF) and (ii) 20 min of deprotection with $20 \%$ piperidine-DMF. After the cleavage of resin with 3

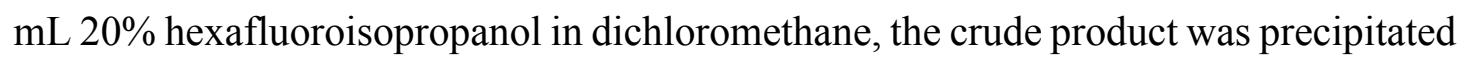
with ether and further purified by preparative HPLC with method B. The r.t. of BocMVK-Dde on analytical HPLC using method B was 16.8 min with a purity $>95 \%$. The overall yield is about $36 \%$ with mass of $640[\mathrm{M}-\mathrm{H}]-{ }^{1} \mathrm{H}$ NMR $\left(\mathrm{CDCl}_{3}, 300 \mathrm{MHz}\right): \delta$ $13.26(1 \mathrm{H}, \mathrm{s}), 7.41(1 \mathrm{H}, \mathrm{d}, J=8.7 \mathrm{~Hz}), 7.21(1 \mathrm{H}, \mathrm{d}, J=6.9 \mathrm{~Hz}), 5.50(1 \mathrm{H}, \mathrm{d}, J=7.2$ $\mathrm{Hz}), 4.56(1 \mathrm{H}, \mathrm{m}), 4.43(1 \mathrm{H}$, septet, $J=6.3 \mathrm{~Hz}), 4.34(2 \mathrm{H}, \mathrm{m}), 3.43(2 \mathrm{H}, \mathrm{dt}, J=5.4 \mathrm{~Hz}$, 
$J=6.08 \mathrm{~Hz}), 2.54(5 \mathrm{H}, \mathrm{br}), 2.39(4 \mathrm{H}, \mathrm{s}), 2.07(3 \mathrm{H}, \mathrm{s}), 1.92(2 \mathrm{H}, \mathrm{m}), 1.73(2 \mathrm{H}, \mathrm{m}), 1.50$ $(2 \mathrm{H}, \mathrm{m}), 1.43(9 \mathrm{H}, \mathrm{s}), 1.26(2 \mathrm{H}, \mathrm{m}), 1.03(6 \mathrm{H}, \mathrm{s}), 0.93(6 \mathrm{H}, \mathrm{dd}, J=6.85 \mathrm{~Hz}, J=7.21$ $\mathrm{Hz}) .{ }^{13} \mathrm{C} \mathrm{NMR}\left(\mathrm{CDCl}_{3}, 300 \mathrm{MHz}\right): \delta 198.53,174.24,172.49,171.41,155.81,107.90$, $80.55,58.71,53.84,52.45,52.14,43.32,31.48,31.31,30.74,30.21,30.14,28.28,28.16$, $22.68,19.21,18.22,17.84,15.28$

\section{Synthesis of NOTA-Met-OH}

p-SCN-Bn-NOTA (10 mg, 1 eq.) was dissolved in $0.5 \mathrm{~mL}$ DMSO, then $\mathrm{L}^{-\mathrm{NH}_{2}-\mathrm{Met}}$ $\mathrm{OH}$ (2.8 mg 1.05 eq.) was added, followed by addition of 5 eq. of tri ethylamine. The reaction was stirred at room temperature until full conversion into NOTA-Met-OH was observed by HPLC analysis. Then the mixture was purified on preparative HPLC to give NOTA-Met-OH in a chemical purity $>95 \%$ and a chemical yield of $75 \%$. The r.t. of NOTA-Met-OH on analytical HPLC using method A was 20.0 min. LC-MS analysis confirmed mass of 598 [M-H]-. ${ }^{1} \mathrm{H}$ NMR (MeOD, $\left.300 \mathrm{MHz}\right): \delta 7.43(2 \mathrm{H}, \mathrm{d}, J=8.4$ $\mathrm{Hz}), 7.30(2 \mathrm{H}, \mathrm{d}, J=7.8 \mathrm{~Hz}), 5.22(1 \mathrm{H}, \mathrm{m}), 3.92(4 \mathrm{H}, \mathrm{br}), 3.59(1 \mathrm{H}, \mathrm{d}, J=18 \mathrm{~Hz}), 3.0-$ 3.3 (14H, br), 2.23-2.32 (2H, br), 2.10 (3H, s). ${ }^{13} \mathrm{C}$ NMR (MeOD, $\left.300 \mathrm{MHz}\right): \delta 182.96$, $175.51,175.34,173.09,170.91,138.67,137.02,131.10,130.90,126.04,60.96,57.71$, $55.95,55.71,54.85,53.25,46.76,44.66,35.46,32.73,31.14,15.46$.

Synthesis of non-radioactive standards of Ga-NOTA-Met-OH and Ga-NOTA MVK-Cys ${ }^{40}$ - Leu ${ }^{14}$-Exendin 4

$50 \mathrm{mM} \mathrm{GaCl}_{3}$ solution ( $\mathrm{pH}=4$ ) was prepared by dissolving $10 \mathrm{mg}(57 \mu \mathrm{mol}) \mathrm{GaCl}_{3}$ in $500 \mu \mathrm{L} 0.6 \mathrm{M} \mathrm{HCl}$, followed by mixing with $600 \mu \mathrm{L} 1 \mathrm{M}$ 4-(2-hydroxyethyl)-1piperazineethanesulfonic acid (HEPES). The non-radioactive gallium complex was prepared by reacting 1 eq. of each of the NOTA-Met-OH $(1 \mathrm{mg}, 1.7 \mu \mathrm{mol})$ and NOTAMVK-Cys ${ }^{40}$-Leu ${ }^{14}$-Exendin $4(1 \mathrm{mg}, 0.2 \mu \mathrm{mol})$ with 20 eq. $\mathrm{GaCl}_{3}$ at $37^{\circ} \mathrm{C}$ for $2 \mathrm{~h}$. The crude mixture was purified by semi-preparative HPLC with method A to give GaNOTA-Met-OH and Ga-NOTA-MVK-Cys ${ }^{40}$ - Leu ${ }^{14}$-Exendin 4 in a chemical purity $>$ $95 \%$ and a chemical yield $>90 \%$. The r.t. of Ga-NOTA-Met-OH and Ga-NOTA-MVK$\mathrm{Cys}^{40}{ }^{4}$ Leu ${ }^{14}$-Exendin 4 on analytical HPLC using method A was 16.1 min and 27.4 
respectively. LC-MS analysis confirmed mass of $665.9[\mathrm{M}+\mathrm{H}]^{+}$for Ga-NOTA-Met$\mathrm{OH}$ and 5245 [M-H]- for Ga-NOTA-MVK-Cys ${ }^{40}-\mathrm{Leu}^{14}$-Exendin 4.

\section{Reference}

(1) Ben Azzouna, R., Guez, A., Benali, K., Al-Shoukr, F., Gonzalez, W., Karoyan, P., Rouzet, F., and Le Guludec, D. (2017) Synthesis, gallium labelling and characterization of P04087, a functionalized phosphatidylserine-binding peptide. EJNMMI Radiopharm. Chem. 2, 3. 

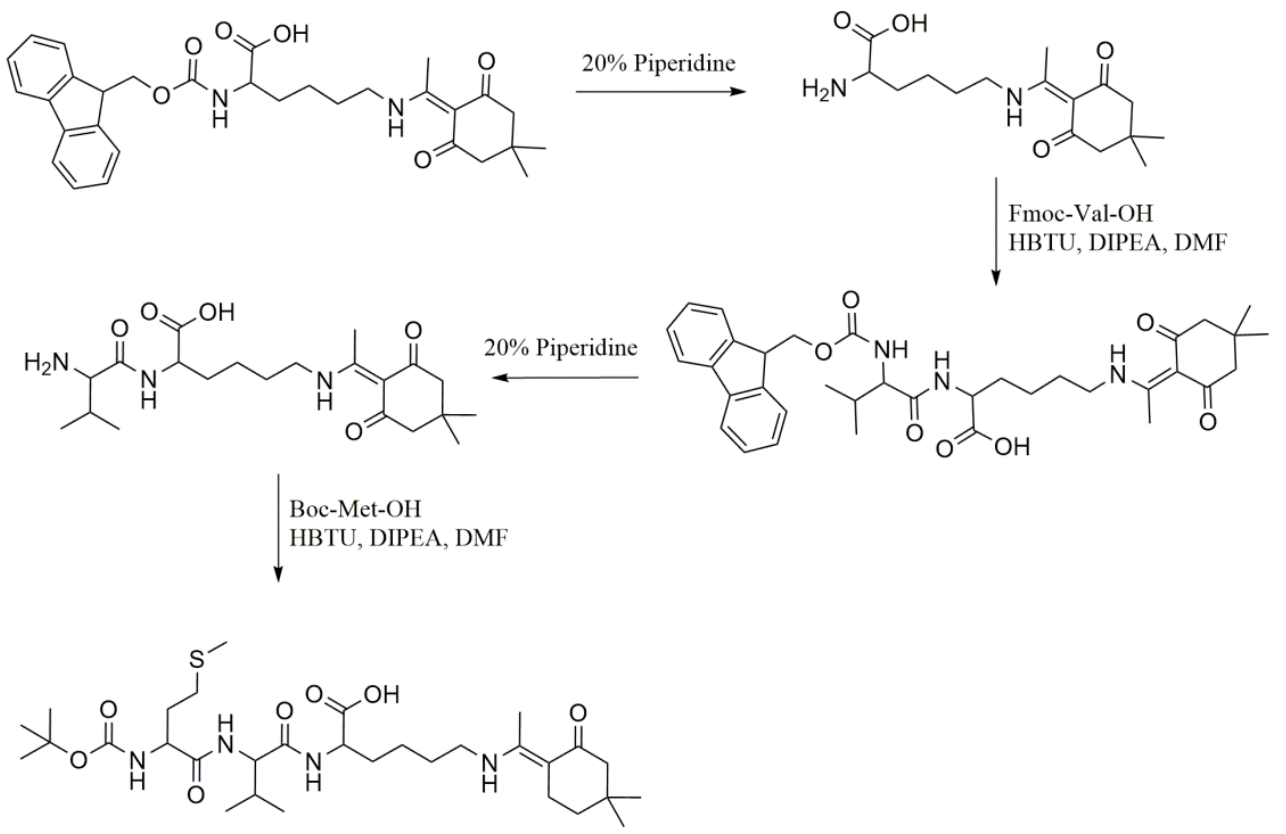

Figure S1. Synthetic route for Boc-MCK-Dde. 


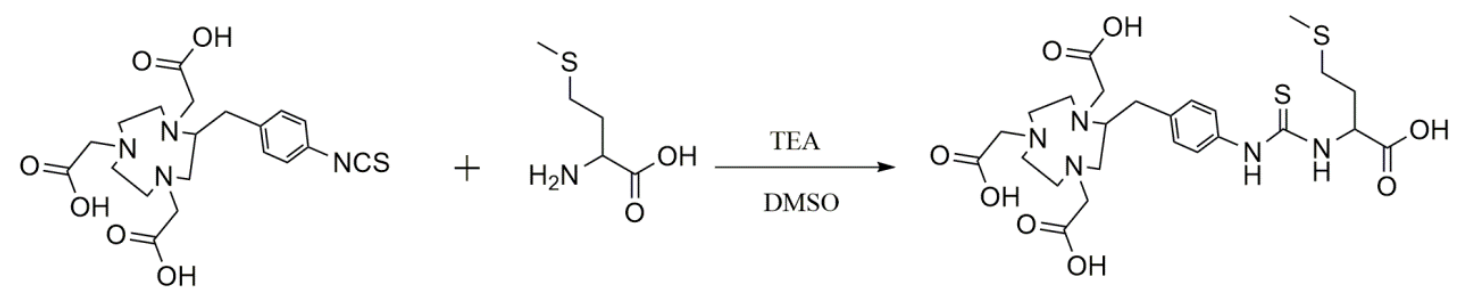

Figure S2. Synthetic route for NOTA-Met-OH. 


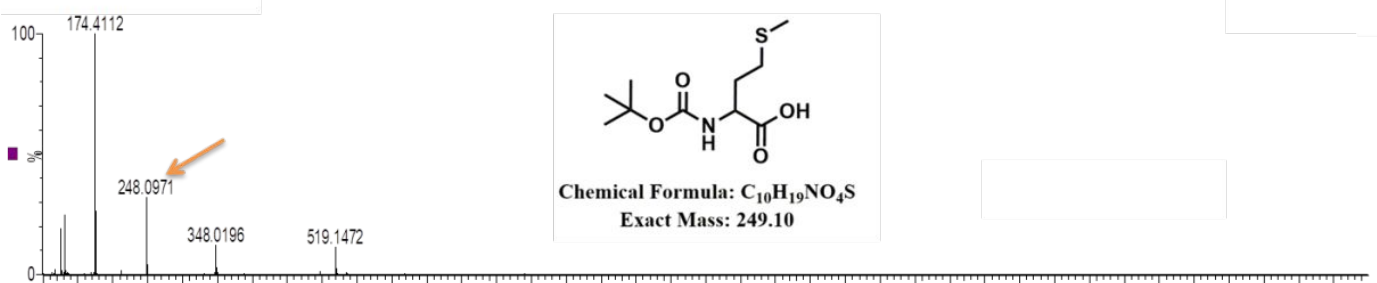

Figure S3 The negative charge MS confirmation of Boc-Met-OH. 
